\title{
Content-Based Analysis of Bumper Stickers in Jordan
}

\author{
Abdullah A. Jaradat \\ Department of English Language \& Literature, Hashemite University, Zarqa, Jordan \\ E-mail: abdjaradat@gmail.com
}

Doi:10.7575/aiac.alls.v.7n.6p.253

Received: 11/10/2016

URL: http://dx.doi.org/10.7575/aiac.alls.v.7n.6p.253

Accepted: 25/11/2016

\begin{abstract}
This study has set out to investigate bumper stickers in Jordan focusing mainly on the themes of the stickers. The study hypothesized that bumper stickers in Jordan reflect a wide range of topics including social, economic, and political. Due to being the first study of this phenomenon, the study has adopted content-based analysis to determine the basic topics. The study has found that the purpose of most bumper sticker is fun and humor; most of them are not serious and do not carry any biting messages. They do not present any criticism to the most dominant problems at the level of society including racism, nepotism, anti-feminism, inflation, high taxes, and refugees. Another finding is that politics is still a taboo; no political bumper stickers were found in Jordan. Finally, the themes the stickers targeted are: lessons of life $28.85 \%$; challenging or warning other drivers $16 \%$; funny notes about social issues $12 \%$; religious sayings $8 \%$; treating the car as a female $7 \%$; the low economic status of the driver $6 \%$; love and treachery $5.5 \%$; the prestigious status of the car 5\%; envy 4\%; nicknames for the car or the driver 4\%; irony $3 \%$; and English sayings $1.5 \%$.
\end{abstract}

Keywords: bumper stickers, themes, politics

\section{Introduction}

The wide spread of vehicles in general and cars in specific has led to a great extent of freedom considered unprecedented in its conventions and manifestations. Cars have enabled people to move from one place to another easily and freely, and they have given people the ability to reach destinations that were considered unreachable in the past. Cars are generally speaking considered valuable properties; a fact which makes them territories permissible to owners but forbidden to others. Cars are considered an extension of the self and a reflection of one's personality, preferences and attitudes. As a result of this, cars have provided owners with moving venues through which owners can express their opinions or attitudes towards a certain issue, a group of people, an event or even a belief. Sometimes, carowners write famous sayings, such as proverbs or wise sayings that - they believe - reflect their experiences in life. These statements or sentences are usually written on bumpers, hence the name bumper stickers. However, Chiluwa (2008) says that stickers can appear on other vehicles and on other places; a fact which explains his use of the term vehicle stickers.

Bumper stickers are generally brief, clear, large-in-size statements written on vehicle bumpers. The brevity of the stickers results from two factors. The first is lack of space. They are written on pumpers which are not big enough to fit more than one statement. The second factor is time shortage; people, whether drivers or pedestrians do not have the time to read more than one sentence in the 2 or 3 seconds they have while overtaking the other car or when the vehicle is passing.

Clarity which means lack of ambiguity stems from the fact that the stickers are addressed to the public, not to a certain class or a specific group. This makes them easy to comprehend and accessible to all levels of community. Clarity also stems from shortage of time. Drivers barley have the time to read bumper stickers, not to mention analyzing them.

The size matter stems from the mobility of the drivers. The stickers are usually written noticeably so that passing drivers and pedestrians can read them easily. The size matter also stems from shortage of time. Passing drivers or pedestrians do not have enough time to read a sticker written in a small font.

This paper attempts to analyze the contents of bumper stickers in Jordan in order to specify their thematic features. To clarify, it will analyze bumper stickers in Jordan according to their topics to determine the most frequent topics in society. The paper will also determine which topics are still considered taboos in Jordan. It will not relate the topics of bumper stickers to any social factor like age, gender, occupation, income, or education.

The paper is organized as follows. In section two, a theoretical background is provided. This section presents the basic principles of content analysis. Section three provides the previous studies that have been conducted about bumper stickers. Section four includes the methodology of the study, while section five provides the findings of the study followed by the discussion in section six. The conclusion is the last section of the paper. 


\section{Theoretical Background}

According to Kim and Kulis (2010) content analysis is 'a widely-used research method for objective examination of communication content' ( $\mathrm{p}$ 369). This statement shows that in content analysis researchers analyze data objectively without predetermined purposes. Kim and Kulis also added that this method is beneficial in unveiling and determining the writers' (in this case car-owners) preferences and behaviors.

Holsti (1969) says that content analysis includes the application of scientific methods to documentary evidence. Neundorf (2012) says that content analysis makes the analysis of data structured and liable to be used in both qualitative and quantitative research.

Krippendorff (1980) says that the quantitative aspect of content analysis provides valid and reliable inferences from data to their context. He introduces the following benefits of content analysis:

1. It is unobtrusive

2. It is unstructured

3. It is context-sensitive

4. It examines the artifact (text, image) of communication and not the individual directly.

Kinnear and Taylor (1991) say that the outcome of content analysis is usually less biased and more objective when compared to other techniques such as questionnaires, surveys and interviews.

Moreover, conducting content-analysis is quite simple and economical when compared to other techniques. Researchers can reach the content without referring to or having to deal with the users. In other words, we can reach bumper stickers without having to deal with the drivers or the owners themselves.

Holsti (1969) says that the large quantities of data can be used to examine the trends and the patterns of content, here bumper stickers.

Finally, it is worth mentioning here that I chose to follow this approach since my study is the first one to study this linguistic phenomenon in Jordan. I decided to adopt this method to determine the major themes that are expressed in bumper stickers which supposedly reflect the main interests of Jordanians as a community.

\section{Bumper Stickers: Previous studies}

Over the past few years, bumper stickers have become a very common phenomenon of expressing opinions, attitudes, and beliefs. The spread of bumper stickers was preceded by the spread of vehicles of all types and mostly cars which are considered in Jordan precious properties due to their high prices resulting from the high taxes levied on them.

In this sense, Belk (1988) says that 'cars serve as an important extension of the self.' Cars are considered by their owners as territories on which they can show their ideas and their love to other people or the vehicle through bumper stickers.

Block (2000) who studied political bumper stickers in Isreal states that bumper stickers 'are non-traditional means of self-expression.' In other words, they reflect the owner's attitudes, and beliefs towards political, economic, educational and social issues. The medium has become a public forum which is accessible to every vehicle owner. Block describes bumper stickers as a new realm of communication that has been 'developed by ordinary people for their own use.' She adds that bumper stickers are used throughout the year in response to daily political, social, or economic events.

Szlemko et al (2008) who studied territorial markings and their relationships to driver aggression and road rage considered bumper stickers as markings of territory. They found that bumper stickers were the most common means of indicating territory among the studied drivers.

Stern and Soloman (1992) say that bumper stickers are 'powerful symbols that express cultural values such as power, freedom, materialism, success, and individualism. Bumper stickers can be considered as communication medium for drivers. They are also an outlet for creativity through which drivers can prove their creativity at the level of form and function. Some drivers view bumper stickers as a kind of decoration or ornamentation. It can be argued that drivers attach pumper for various purposes. Block (2000) says that some do this as an affirmation of cultural identity.

Chiluwa (2008) who studied religious vehicle stickers in Nigeria, found that the stickers could be used by individuals to express their religious relationships, social values, or political attachments. He found that religious stickers could be used to express three main themes: 1) social vision, 2) group identity, and 3) reaffirmation of faith. It is obvious that the study has not accessed other themes stickers might express; it has focused on religion only.

Similarly, other studies were oriented towards one theme, mostly, politics. Block (2000) who studied political bumper stickers in Israel states that bumper stickers are used a means of protest against unfavorable political events. Jay Nordlinger (2015) described the frequency of the phenomenon in the United States from a personal perspective where he talked about some political stickers and related them to their political context. Burt and Simes (2015) talked about the role of bumper stickers in foreign policy in the United States. The said that bumper stickers in the US reflected the people's attitudes towards the US government's policy during the cold war, the Vietnam War, and presidential campaigns. Nordlinger (2015) provided more examples of bumper stickers in the US saying that they reflected people's attitudes towards serious issues like abortion, the nuclear weapons, war, and presidential campaigns.

Haynsworth (2008) talked about the unintended and largely negative consequences of the meanings of bumper stickers. She referred to specific situations where what you mean may not be understood by the readers the way you intended. 
She gave examples on presidential campaigns and on people who were fined or ticketed or even fired from job as a punishment for the negative meanings of the stickers they have on their vehicles.

Norton-Meier (2004) stated that bumper stickers could be used as a means of teaching children letters, words, shapes, colors, and designs. In other words, bumper stickers aside from their content are influential in literacy and knowledge for children.

Despite their widespread distribution and its accessibility to all levels of the community in Jordan, little academic attention has been given to the topic. This is because people as well as scholars on the same footing believe that stickers are not worth studying. No previous study as far as the researcher knows has been conducted on this topic in Jordan.

\section{Methodology}

The statements on bumpers or what is called bumper stickers were collected by the researcher himself over a period of a year through which he intentionally and unintentionally was on the road - parking, driving, and walking, looking at car bumpers and trunks searching for them. The researcher also asked friends and students to provide him with as many bumper stickers as possible, and they did not hesitate to do so. A total number of 218 bumper stickers were collected. The stickers were then classified and distributed according to their themes which were suggested and approved by the students of the Sociolinguistics class the researcher is regularly teaching at the Hashemite University in Jordan. The frequency and the percentage of the stickers in each theme in comparison to the total number of bumper stickers are then provided.

Table 1. The themes, the frequency and the percentage of bumper stickers in each theme

\begin{tabular}{lll}
\hline The theme & Frequency & Percentage \\
\hline Experiences/ lessons from life & 63 & 28.85 \\
\hline Challenging or warning other drivers & 35 & 16.1 \\
\hline Funny notes about social issues & 26 & 11.92 \\
\hline Religious & 18 & 8.3 \\
\hline Femininization/ treating the car as a female & 16 & 7.3 \\
\hline The low economic status of the driver & 13 & 6 \\
\hline Romance/ love and treachery & 12 & 5.5 \\
\hline The size or the prestigious status of the car & 10 & 4.6 \\
\hline Envy & 9 & 4 \\
\hline Nicknames & 8 & 3.7 \\
\hline Irony & 6 & 2.75 \\
\hline English & 3 & 1.38 \\
\hline Total & 218 & 100 \\
\hline
\end{tabular}

\section{Findings}

This section will present the basic themes that the bumpers stickers carry, the number of bumper stickers in each theme as well as the percentage of each theme in comparison to the total number of bumpers stickers. In addition, some explanations of stickers are given here. The following sections present the most frequent topics that appeared in bumper stickers in Jordan supported with extensive examples.

\subsection{Experiences of Life}

The number of stickers in this section is 63 which make nearly $29 \%$ of the whole group. This group includes general statements about experiences in life with regard the driver's attitude towards other people; his miserable situation at the financial level basically; his hopes; lack of luck, family issues, etc. The stickers are typically negative in content since they express lessons people learned the hard way while dealing with others. Some stickers describe the behavior of people when they are in need of others. Generallyspeaking, people are depicted as having negative attributes. Consider the following examples:

1. The sea is salty and the people are beneficial/ exploiters.

2. But for interests, nobody would be good.

3. He who keeps watching people will surely die of despair.

4. When in need of you the dogs would come hastily.

Sticker (1) contains a lesson the driver learned from life that people accompany other people to obtain certain benefits and they tend to abandon them when the goals are obtained. Sticker (2) repeats the same theme in a different way. Sticker (3) says that he who keeps looking at people and wishing to get what they have without having any means through which he or she can achieve what they would like to have, will die out of despair since they cannot get what 
people have by simply looking and wishing. Sticker (4) repeats the same theme of stickers (1) and (2) but in a different way.

Another group of stickers describes the miserable situation of the owner of the car again because of people treachery and mistrust. Consider the following examples:

5. I loved travelling because of the people's treachery.

6. Because of my worries, I became a public driver (to run or to forget his worries).

7. No hope/ there is no hope

8. I doesn't matter anymore

All the stickers in this group emphasize the fact that the driver or the car owner has suffered a lot from people's mistrust and dishonesty; a fact which led him to love travelling as in (5), or to become a public driver as in (6), or to have certain absurd convictions that do not usually reflect his personality and belief as in (7) and (8)

A third group of stickers describe the miserable situation of the driver as a result of previous romantic experiences which may make the driver develop weird thoughts or beliefs. The following are the best the examples:

9. Always tears

10. I sincerely loved him/her, but she/he was a deceiver.

11. The woman's right is the kitchen

The last one seems to be a reaction to one's failure in a love relationship with a certain female who deceived him, got married or forced to marry another man. As a reaction, the driver believes woman's rights can be found in the kitchen, not the university or any other institution. Moreover, this sticker is the only one with carries some prejudice against women.

Finally, the last group of stickers presents some general, funny, but wise statements that can also be viewed as lessons about life. Consider the following examples:

12. When I was a bird they ate me; when I became a lion, they accompanied me.

13. When I was born, the devil said: "the challenge has just started."

14. Even to hell, we can take you (a public driver)

15. All people's comments are unanswered calls.

Sticker (12) says that one must live as a lion in a jungle, otherwise, he will be mistreated or even exploited. In sticker (13), the driver is bragging that people must be cautious when dealing with him since he is deemed by the devil as the only challenge the devil has met through life. Sticker (14) is said by a taxi driver who is apparently suffering from lack of money and who does not mind destination as long as the passenger will pay the fare. In (15), the driver does not care about what people say; the driver believes that all what people say does not make any sense for him as if he has not heard what they have said at all.

\subsection{Funny Notes}

The number of stickers in this group is 26 and they make up nearly 12 percent. These stickers include funny statements that are untrue or unreal or that do not express a true lesson about life. The function of these stickers is to make you as a reader laugh or reflect the driver's sense of humor. Consider the following examples:

16. He who has money and does not know what to do with it should buy pigeons and fly them.

17. Do you know a person who knows another person who knows me?

18. If you tell your secret to a tongue-tied woman, she will talk, by the will of Allah.

19. The goal of my life has been an offside.

20. The doors of the car are unlocked, do not break the window (Dear thief)

Two points need to be raised here. The first is that most of these stickers are not totally novel. Most of them are, in fact, repeated or borrowed from other drivers i.e. they can be found on several cars. The second is that some of them are well-known proverbs like example (16) above. This proverb has nothing to do with cars and drivers, but it seems that the driver liked it and attached it to the bumper of his car.

In (19) above, the driver plays on words by using the word goal. A goal of life can never be an offside; however, a goal in football match can. The driver mixed between the two fields. It is this mixture that makes the sticker funny.

\subsection{Challenge}

The stickers here carry the meaning of a challenge to other drivers or a warning not to try to match the driver in his driving skills or to speed him. The driver is asking other drivers not to commit any action that might mean a challenge or rivalry. Consider the following examples:

21. Do not try to overtake me.

22. Do not challenge the hawk, you pigeon.

23. Do not think I am not a good driver if you see me driving slowly; increase your speed and see me then.

24. Pass and go and do not challenge me.

25. If you don't like what I'm doing, go and pluck your eyebrows 
As can be noticed from these examples, the tone of challenge is witnessed through the use of imperatives and negative imperatives. The drivers are commanding other drivers not to challenge them. The exact number of stickers expressing a challenge is 35 and these constitute more than 16 percent of the total number of stickers.

Some stickers may indicate a challenge because of certain beliefs the driver has. In the following example, the driver says frankly that he is a fan of Barcelona soccer team. He also asks people who do not like this fact to commit suicide:

26. I am a fan of Barcelona Soccer Team, and I am proud of it, and those who do not like this should go and commit suicide

Other challenge stickers are simply funny. One driver wrote "race it and take it", while another said "the driver is flammable" to indicate that the driver is a very nervous person whom you should not approach or challenge.

\subsection{Religious Stickers}

The number of stickers in this category is 18 and they constitute more than 8 percent of the total number of stickers. These stickers do not intend to have religious lessons and preaches. They are simply religious expressions that one says to protect himself, his family, his possession, especially the car from envy and harm as in the following examples:

27. May Allah protect you (i.e. the car).

28. Take a look and pray on the Prophet (Peace be upon him).

29. It is by thanking (Allah) that graces last.

30. (The car is) coming back by the will of Allah.

31. Whatever Allah will, will take place.

In Islam, envy is harmful. Prophet Mohammad (PBUH) says that in order to protect family, oneself, or possessions from envy or so as not to appear as envious, one should say the expression 'by the will of Allah' which appears in (30). Owners of cars are seeking to protect their cars from envy by writing these stickers.

Some other expressions are simply reflecting the religious orientation of the driver as in:

32. Perfume you mouth by praying on Prophet Mohammad (PBUH).

33. I wish to gain the satisfaction of Allah and the satisfaction of my parents.

34. The head of wisdom is the fear from the Allah.

The driver is wishing to gain rewards from Allah by reminding himself and others to do these acts or to say certain expressions.

\subsection{The Low Economic Situation of the Driver}

The stickers in this group indicate that the driver has a small old car due to his miserable economic situation. However, most of these stickers are simply funny since

35. The destiny of the small is to be big.

36. Do not be cheated by the old Beatle I am driving; the Range Rover is at home.

37. An Old Beatle is better than a Mercedes Bens car that comes in debts.

38. A Lada is better than the favor of this and that.

39. The Porsche is with the madam (The driver's wife)

In (35), the driver is driving a small cheap car; however, he is assuring other drivers that the destiny of the small is to become bigger one day i.e. he will buy a better car one day. In (36), the driver has a sense of humor; he is driving a small old car. Neither he nor his wife has another car. He is just making fun or expressing his sense of humor by this statement. In (37), the driver is trying to comfort himself by the fact that a small old car is better than a Mercedes car, which is greatly appreciated and extremely expensive in Jordan, which is bought through debts. In (38), the driver comforting himself by his belief that driving an old car like a Lada, a car which has low status in Jordan, is better than asking other people to give him a ride or to borrow their cars. (39) is similar to (35); the driver does not have any other car but the old car he is driving; however, he is expressing his sense of humor. He says do not think this is the only car I have; I have a Porsche which is driven by my wife right now.

The stickers in this category is 13 making up to 6 percent of the total number of stickers.

5.5 Love

As shown in the table, the number of stickers expressing love is 12 forming around 6 percent of total number of stickers. This number is relatively among the lowest, though the researcher expected it to be higher. These stickers express the driver's current or previous love experiences towards a female without mentioning the name of the female. Consider these examples:

40. Among all the people, I chose you.

41. You alone are my love.

42. I love my mother-in-low since she gave birth to my life.

43. I swear by Allah that I married the girl I loved.

44. She said farewell.

45. Your fault made you less dear.

Generally speaking, most cars with stickers are driven by males. However, in (40) and (41), although the driver is a male, the masculine pronoun is used since sometimes these statement are spoken by a female to a male. The sticker in 
(42) is funny since generally speaking mothers-in-law are rarely loved by the husband. The driver considered his wife his life. In (43), the driver is making an oath that he has married the girl he loved which rarely takes place in Jordan since sometimes parents when discovering that their daughters were having a love relationship even if it was pure, prevent her from seeing her love or force her to marry to another person. Therefore, marrying the girl you loved when you were young is sometimes something miraculous. Sticker (44) expresses the driver's sadness on the farewell of his beloved. Sticker (45) contains a rebuke to the addressee whether a male or a female that due to his or her mistake, their status has become lower in the heart of the speaker.

\subsection{Femininization/ Treating the car as a female}

The number of the stickers in this category is 11 and these constitute $5 \%$ of the total number. Through these statements the driver is treating the car as female he loves and appreciates. The car is as dear to the driver as his beloved. The car is something precious. Consider the following examples:

46. Do not follow me; I am engaged.

47. The spoiled girl of Abu Habib

48. The beautiful Tala

49. Oh Dyna, you're so lucky; your rider is Ali

In (46), the car is treated as a woman who is engaged and who is asking other drivers not to follow her; in (47), the car is considered as a spoiled girl who gives him joy and pleasure; a fact which makes the driver decorate the car with chrome and polish. In (48), the car is given a name; which could be the name of the real beloved of the driver or a fictitious one. In (49), the driver is addressing his car or truck saying that she is so lucky for having him as a driver. This example is really interesting since it is borrowed from a Syrian series that is about a taxi-driver who used to treat his car as a mare and to consider himself as the rider of the mare.

\subsection{The size or the high status of the car}

The number of these stickers is 10 forming around 5 percent. These stickers usually appear on big vehicles or prestigious ones. The stickers will be divided into two groups accordingly.

The first group appears on big vehicles such as road rollers, bulldozers, earthmovers, and tank trucks which are considered big in comparison to cars and other small vehicles. This group includes:

50. It is the right of the heavy to be spoiled i.e. to walk slowly and arrogantly

51. Make space for the big

52. When the big goes down, there will be no space for others.

53. If you are clever, come from the front (written on a road roller)

54. If you are clever, come from the back (written on a sewage water tanker)

Sticker (50) says that it is the right of big vehicles to walk slowly. Of course they walk slowly because of the size; however, the driver meant that they walk slowly because of arrogance. Sticker (51) asks drivers to move away from the road when they are trodden by big vehicles. The sticker carries an implicit threatening meaning which says 'otherwise you will be forced to move.' Sticker (52) carries the same meaning of the previous sticker. Sticker (53) is a funny one which is written on a road roller; it carries the meanings of challenge and threatening. The driver is challenging drivers of other vehicles to face him or to stand in front of his vehicle. Sticker (54) is written on a sewage water tanker; a vehicle that no one likes to follow due to the noisome smell that issues from the material the tanker carries and to the drops of liquid that might leak from the tanker while moving.

The second group includes stickers that indicate the prestigious status of the car. It seems that Mercedes Bens is the most respectful brand for cars in Jordan. This explains the appearance of this brand in some stickers including:

55. The Mercedes talks while the others are in pain.

56. The ghost is at home.

Sticker (55) shows the prestigious status of Mercedes Bens vehicles; it says that these cars have the final word in everything. When a Mercedes Bens car treads the road, other drivers are in pain wishing to own one instead of theirs or deploring why they do not have one like it. Sticker (56) contains a popular name for one type of Mercedes Bens cars. The name is ghost. The driver asks other people whether pedestrians or drivers not to think that he is poor because of the car he is driving; the ghost i.e. the most prestigious car you can think of, is at home.

5.8 Envy

These stickers directly touch the issue of envy. It is deeply rooted in Jordanian's Islamic and popular beliefs that envy leads to the disappearance of the grace (e.g. health, wealth, or status) or the object (e.g. car, house, or jewelry) you own. Islam tells Muslims that envy can lead to death, and asks Muslims to says certain expressions if they saw something they admired owned by others. Islam asks Muslims to say an expression like 'this is what Allah determined' to make them content that whatever they will do, they will not be able gain anything unless Allah determine so. The number of the stickers is 9 and they make up 4 percent of the total number of stickers.

These stickers are not religious nor do they carry religious connotations. They simply ask the reader not to envy them. It is worth mentioning here that some of these stickers are traditional sayings. Consider the following examples:

57. Do not harm us with your looks, I bought through debts.

58. The eyes of he who envies us should receive a stick 
59. (watch)Your looks/eyes; by Allah, it is bought by debts.

60. The bite of a lion, but not the look of envy

Sticker (57) asks seers not to harm the driver and his car by his look i.e. not to envy them; the directive is accompanied with an excuse for not doing so. The driver tells other people that the car was bought through debts i.e. through financing from banks. Sticker (58) contains a traditional saying which is used in all situations of life. Sticker (59) asks viewers to look at the car with no envy. It is a repetition of sticker (57) nevertheless the idea is emphasized highly here since it contains an oath by Allah. The driver in sticker (60) prefers to bitten by a lion to receive a look of envy. The word 'lion' is chosen for different reasons. First, it rhymes with envy in Arabic. Second, the lion is the king of the jungle, and the driver would rather be bitten by the king of the jungle a case he would be recovered from on the long run, to receive a look of envy which might wipe out his health, wealth and descendents. Through this comparison, the driver seeks to emphasize the negative influence of a look of envy.

\section{9 Nicknames}

Some stickers contain nicknames the drivers used to refer to themselves or to their vehicles. Two distinctive characteristics are detected in these stickers; one relates to their size the other relates to the type of the vehicles that carry them. The first is that these stickers are brief i.e. containing one or two words, and this stems from the fact that they are nicknames which are usually short. The second is that these stickers are usually written on pickups or cargo trucks. Consider the following examples:

61. The ship of the desert

62. The princess of the south

63. The scorpion

64. The impossible

In (61), the driver considers his truck as the ship of the desert since maybe most of his trips are in the desert. Sticker (62) indicates that the driver usually drives his truck most of the time in the southern part of Jordan, hence the nickname given above. The nickname in (63) may refer to the vehicle itself or the driver himself. Regardless of the reference, the sticker indicates the vehicle and the driver should be approached with caution and should be feared. The same thing can be said about sticker (64). The driver and the vehicle are performing miraculous deeds whether in speeding or in reaching far destinations, hence the name the impossible.

Finally, the exact number of these stickers is 8 and they constitute $3.7 \%$ of the total number of stickers understudy.

5.10. Irony

These stickers are closely related to the funny stickers given in 4.2. since they funny in essence; however, they are different in since they are based on irony. The number of these stickers is 6 and they make up around 3 percent.

The first part of these stickers makes you predict a natural second part, but the second part comes with unpredictable meaning. Most of them contain adaptations of known proverbs or sayings. Consider the following examples:

65. He who eats alone will eat enough/ will reach saturation

66. The winds come full of sand

67. Why are you carrying in your heart, and there are sacks every where

68. If you are in a hurry, leave early

Sticker (65) contains a modification of an old saying which says 'if you eat alone, you will choke.' I think that the driver simply liked the sentence and so he wrote on his bumper. Sticker (66) is an adaptation of the old verse of poetry 'winds come with what ships hate.' The first part of sticker (67) gives the reader the implication that the driver is really caring since it is usually addressed to a person who is melancholic and depressed asking him or her to talk about troubles and misery. However, the second part comes with unpredictable consequence. The irony stems from treating the phrase 'carry in heart' literally, which explains the usage of sacks in the second part of the sticker. Sticker (68) contains a message to speeding drivers that if you were in a hurry, you should have left earlier instead of speeding, overtaking, urging others to make space for you to speed and all the wrong deeds you might commit.

5.11 English

Three stickers that are completely English or containing English words were found. The three are listed below:

69. Don't speak لابلش فيك

70. No time for love

71. Baby on board

Sticker (69) is a threatening for others to keep silent so as not to encounter grave consequences; the literal meaning of the Arabic phrase is 'so as not to deal with you.' Sticker (70) is a phrase that is usually uttered by practical people who do not have time for romantic issues or by people who previously has a regretful romantic relationship. Sticker (71) tells that there is a baby on board; however, the sticker does not indicate that there is a baby on board. The driver might have loved the sticker or the way it looks like on a yellow plate.

\section{Discussion: General implications}

This section will present general statements about the findings presented in the previous section. The statements aim at interpreting the stickers as a linguistic phenomenon in Jordan. 
The first major observation is that the themes reflected in bumper stickers are written in Arabic except for the three stickers mentioned above. Moreover, the themes of the stickers are varied and reflect the social, economic, romantic, religious, and personal orientations of Jordanians as a group and as individuals.

The second major observation is that, unlike what is common in Israel or the United States, no political stickers whatsoever whether supporting or criticizing appear on Jordanian cars. Although Jordan is a democratic country, and the government encourages the establishment of parties, and encourages young people to get involved in political life through joining parties, no political stickers were observed. It seems that visual political representations whether slogans or logos which are not sponsored by the government are still considered taboos in Jordan.

Related to this issue is the fact that no sticker was found to stand or to show support for any organization, issue, a group of people whether political, social or economic. Most of the stickers regardless of the themes they reflected are mainly used for fun. Moreover, they are not usually taken seriously.

The third finding is that most stickers are harmless in the sense that no racial or biased stickers against a certain group or gender are seen although some stickers showing pride of a certain tribe, family or group were observed.

A fourth finding is that a large number of bumper stickers are repeated in many cars; there is no copyright here. This raises the issue of intertextuality. Some stickers are well-known proverbs that, like most proverbs, carry a lesson in life. In this sense, most stickers are not innovative because they are repeated everywhere. Consider the following examples that are proverbs and wise sayings and were common before being used as stickers:

72. The respect of the big is mandatory

73. He who has money and confused what to do with it should buy pigeons and let them go.

74. Oh! Mountain, surely you will not be affected by the wind

75. He who keeps watching people will die out of despair.

The general statement that can be given about bumper stickers in Jordan is that they do not reflect or criticize the problems the Jordanian community is suffering from like racism, anti-feminism, wasta or nepotism, abundance and accumulation of garbage, shame killing, inflation, and the unexpected and unfavored increase of refugees, let alone the unfavorable actions of the Jordanian government which seeks all the time to levy more taxes on, and which leaves no stone unturned to tighten its grip economically on citizens. In other words, bumper stickers in Jordan, unlike those in the United States and Isreal, do not carry any biting messages of any sort to any governmental site or behavior.

\section{Conclusion}

This paper has argued that pumper stickers are very common among Jordanians and can be viewed as a venue for drivers through which they can express their beliefs and attitudes towards various issues in society.

The research has shown that bumper stickers reflect various themes ranging from individual issues such as identity, territory, and nicknames that are given to vehicles through challenge and speeding to social issues that apply to a wide scale of Jordanians including the difficult economic situation most people are going through, love and lessons from life. The second major finding is that most of the stickers regardless of themes are funny and not serious and determined to reflect the driver's sense of humor. We might say that drivers with stickers might have chosen to attach a sticker on the bumpers of their vehicles because they liked the statement at the level of meaning, or structure or musicality, not because they sincerely reflect what they believe.

The study has also found that political stickers in Jordan are still a taboo in Jordan; although there are no clear governmental directions against doing so, people still believe that politics should be avoided.

A key strength of this study is that it is the first one to study this phenomenon in Jordan; which means it will a base for further future studies about stickers in Jordan. However, the major limitation of the study is its limited scope; it has focused on the themes of the stickers only. This limitation might lead for further research in the field including the structural patterns of bumper stickers in Jordan. Further research could explore the sociolinguistic relationship between stickers and the gender, age, education level, and occupation of the drivers.

\section{References}

Belk, T. (1988). Possessions and the Extended Self. Journal of Historical Research in Marketing, 7(2), PP $184-207$.

Block, L. (2000). Mobile Discourse: Political Bumper Stickers as a Communication Event in Isreal. Journal of Communication, 50(2), pp 48-76.

Burt, R., and Demitri, K.S. (2015). Foreign Policy by Bumper Stickers. The National Interest. September/October Issue. New York.

Chiluwa, I. (2008). Religious Vehicle Stickers in Nigeria: A Discourse of Identity, Faith and Social Vision. Discourse and Communication, 2(4), 371-87.

Haynsworth, L. (2008). My Volvo, My Self: The (Largely Unintended) Existential Implications of Bumper Stickers. Fourth Genre, 10(1), pp 21-34.

Holsti, O. R., (1969). Content Analysis for Social Analysis and Humanities. Reading. Addison-Wesley Publishing, MA. 
Kim, I., and Jasna, K.(2010). Applying Content Analysis t Web-Based Content. Journal of Computing and Information Technology, 4, PP 369-375.

Kinnear, T. C., and Taylor, J.R. (1996). Marketing Research: An Applied Approach. McGraw-Hill Inc, London.

Krippendorf, K. (1980). Content Analysis: An Introduction to Its Methodology. Sage Publication, London.

Neundorf, K. A. (2012). The Content Analysis Guidebook. Sage Publications, London.

Nordlinger, J. (2015). Stick It to 'em: A World of Bumper Stickers. National Review, LXVII(15), pp 26-27. New York.

Norton-Meier, L. A. (2004). The Bumper Sticker Curriculum: Learning from Words on the Backs of Cars. Journal of Adolescent and Adult Literacy, 48(3), PP 260-63.

Stern, B. B, and Soloman, M. R. (1992). "Have You Kissed Your Professor Today?": Bumper Stickers and Consumer Self Statements. Advances in Consumer Research, 19, PP 169-173.

Szlemko, W., Jacob A., Benfield, P.A. Bell, J.L., Deffenbacher, R., and Lucy, T. (2008). Territorial Markings as a Predicator of Driver Aggression and Road Rage. Journal of Applied Social psychology, 38(6), PP 1664-88. 